\title{
A combined Raman spectroscopic and theoretical investigation of fundamental vibrational bands of furfuryl alcohol (2-furanmethanol)
}

Barsberg, S.; Berg, Rolf W.

Published in:

Journal of Physical Chemistry A

Link to article, DOI:

10.1021/jp061642c

Publication date:

2006

Document Version

Early version, also known as pre-print

Link back to DTU Orbit

Citation (APA):

Barsberg, S., \& Berg, R. W. (2006). A combined Raman spectroscopic and theoretical investigation of fundamental vibrational bands of furfuryl alcohol (2-furanmethanol). Journal of Physical Chemistry A, 110(6), 9500-9504. https://doi.org/10.1021/jp061642c

\section{General rights}

Copyright and moral rights for the publications made accessible in the public portal are retained by the authors and/or other copyright owners and it is a condition of accessing publications that users recognise and abide by the legal requirements associated with these rights.

- Users may download and print one copy of any publication from the public portal for the purpose of private study or research.

- You may not further distribute the material or use it for any profit-making activity or commercial gain

- You may freely distribute the URL identifying the publication in the public portal 


\title{
A combined Raman spectroscopic and theoretical investigation of fundamental vibrational bands of furfuryl alcohol (2-furanmethanol)
}

\author{
S. Barsberg*, R. W. Berg** \\ * The Royal Veterinary and Agricultural University, Forest and Landscape, Rolighedsvej 23, DK- \\ 1958 Frederiksberg C, Denmark. \\ ** Technical University of Denmark, Dep. of Chemistry, Kemitorvet, B. 207, DK-2800 Lyngby, \\ Denmark.
}

\begin{abstract}
Furfuryl alcohol (FA) is a promising reactive precursor for new materials. FA reaction mechanisms, e.g., self-reactions or cross reactions with other substances, can be studied by vibrational spectroscopy. We present a Raman spectroscopic and theoretical study of vibrational properties of FA based on density functional theory (DFT/B3LYP), and a recently proposed hybrid approach to the calculation of fundamental frequencies. Excluding one frequency the remaining ones are predicted to a best RMS error of $8 \mathrm{~cm}^{-1}$, and are qualitatively assigned. A CH stretching mode is underestimated by $65 \mathrm{~cm}^{-1}$. This may be due to deficiencies of DFT to model dispersion forces.
\end{abstract}

\section{Introduction}

The vegetal biomass constitutes an enormous renewable source of chemicals. These can be original biomass constituents, e.g., starch, hemicelluloses, cellulose and lignin, or products derived from these. Biomass based chemicals can provide original polymers, which are not readily available via petroleum-based chemistry. An interesting example is furfuryl alcohol (FA), which is industrially produced via conversion from furfural. In the presence of an acidic catalyst FA undergoes a thermally activated polycondensation process, which leads to linear and branched polymers. Several different mechanisms govern this complex process, which leads to progressive coloration and resinification. ${ }^{[1-5]}$

This reactivity of FA is also utilized in a promising process, which substitutes conventional wood impregnation with a more environmentally safe alternative ${ }^{[6,7]}$. The raw wood is first coimpregnated with FA and an acidic catalyst. The impregnated wood is heated, and FA then reacts within the wood cell wall or lumens. The last curing step is not well understood but is likely to involve both self-condensation reactions of FA, as well as cross-condensation reactions between FA and wood cell wall components.

These reactions can be studied using vibrational (IR and Raman) spectroscopy, which provides molecular "fingerprints" and thus information on the reaction products as well as on their origins. The interpretation of vibrational bands is strengthened by application of quantum chemical calculations for predicting normal mode vibrations of appropriate molecular models. Natural choices of such models are oligomeric structures derived either from FA, or from both FA and a model of a cell wall component.

Such efforts rely, however, on an improved knowledge of the basic properties of FA itself. In analogy with allylic alcohols the $\mathrm{C}=\mathrm{C}-\mathrm{C}-\mathrm{O}-\mathrm{H}$ chain leads to different conformational states distinguished by the $\mathrm{C}=\mathrm{C}-\mathrm{C}-\mathrm{O}$ and $\mathrm{C}-\mathrm{C}-\mathrm{O}-\mathrm{H}$ dihedral angels ${ }^{[8]}$. Previous MP2/6-31G(d) work 
identified five different FA conformations, and experimental work indicated that two of these dominate at room temperature ${ }^{[9]}$. In principle any reaction of FA is initiated from all of these five different (thermally populated) initial states, and reaction rates can differ between these five reaction channels.

(Fig. 1)

The present work focuses on the vibrational properties of FA. It was recently shown that the combination of harmonic and anharmonic frequency calculations using Density Functional Theory (DFT) provides unambiguous assignments of vibrational bands with $<10 \mathrm{~cm}^{-1}$ average prediction error for reported cases ${ }^{[10-12]}$. Each frequency is obtained - without use of a scaling procedure - as the sum of a harmonic large basis set frequency and an anharmonic small basis set frequency correction (obtained by a perturbative treatment ${ }^{[13]}$ ), henceforth referred to as a hybrid calculation. We report a combined Raman spectroscopic and theoretical investigation of fundamental vibrational bands of FA. The different conformers of FA and their population probabilities at $\mathrm{T}=$ $298 \mathrm{~K}$ are estimated using DFT. Vibrational band assignments and positions are derived from hybrid DFT frequency calculations and compared with the experimental results.

\section{Experimental}

FA was obtained from Sigma-Aldrich and distilled twice before use. Toluene $(>99.5 \%)$ was obtained from Bie \& Berntsen, Denmark, and carbon tetrachloride (>99.5 \%) from Fluka, Germany.

Raman spectra were obtained by use of a DILOR-XY $800 \mathrm{~mm}$ focal length multichannel spectrometer with horizontal $\mathrm{Ar}^{+}$-ion laser excitation $(514.5 \mathrm{~nm}, \sim 300 \mathrm{~mW}$, vertically polarized and with the Argon plasma lines filtered off with an interference filter). Rayleigh scattered light was filtered off with a double pre-monochromator (with slit widths 200, 2000 and $200 \mu \mathrm{m}$ ). The Raman light was obtained in a $90^{\circ}$ scattering configuration and dispersed by use of an 1800 lines $/ \mathrm{mm}$ grating and focused onto a CCD detector, cooled by liquid nitrogen to $140 \mathrm{~K}$. The spectral resolution was approximately $4 \mathrm{~cm}^{-1}$.

Spectra were obtained first from $1 \mathrm{~mL}$ of solvent (toluene or $\mathrm{C}(\mathrm{Cl})_{4}$ ) - providing a background spectrum - then from the same vial where FA was repeatedly added and mixed in Vol:Vol concentrations of 1.0, 2.1, 6.6 and $13.1 \%$, respectively. Spectra of benzonitrile were obtained at six times evenly dispersed throughout the whole measurement period and used for frequency calibration following the ASTM E 1840 standard. Spectral information, e.g., band frequency positions, was obtained from fitting single Gaussian or Lorenzian profiles to well separate bands and multiple profiles to partly overlapping bands.

Experimental frequency errors were obtained from combining (1.) the published errors (standard deviation) of the ASTM E 1840 standard, (2.) the frequencies standard deviation of benzonitrile bands derived from the six spectra and (3.) the errors of the functional profile fit to experimental bands.

A corrected FA Raman spectrum $\mathrm{I}_{\mathrm{C}}(\mathrm{k})$ was obtained by subtracting an appropriately scaled background solvent spectrum $\mathrm{I}_{\mathrm{S}}(\mathrm{k})$ and a relatively weak structure less fluorescence background $\mathrm{I}_{\mathrm{F}}(\mathrm{k})$ from the raw spectrum $\mathrm{I}(\mathrm{k})$, i.e., $\mathrm{I}_{\mathrm{C}}(\mathrm{k})=\mathrm{I}(\mathrm{k})-\mathrm{f}(\mathrm{k}) \mathrm{I}_{\mathrm{S}}(\mathrm{k})-\mathrm{I}_{\mathrm{F}}(\mathrm{k})$. By recording the intensity change of characteristic solvent peaks - comparing $\mathrm{I}_{\mathrm{S}}(\mathrm{k})$ and $\mathrm{I}(\mathrm{k})$ - it was found that the scaling constant should include a weak linear dependence $\mathrm{f}(\mathrm{k})=\mathrm{A}+\mathrm{Bk}$ on the wavenumber $\mathrm{k}$. The constants $\mathrm{A}$ and $\mathrm{B}$ were 
determined by linear fitting. FA Raman bands in the corrected spectrum were then fitted by either Lorenzian or Gaussian functions depending on fit quality.

The software package G03 was used for predicting molecular properties of FA using density functional theory, i.e., the B3LYP functional, combined with variously sized standard basis sets: 6$31 \mathrm{G}(\mathrm{d}), 6-31 \mathrm{G}(\mathrm{d}, \mathrm{p}), 6-311++\mathrm{G}(\mathrm{d}, \mathrm{p}), 6-311++\mathrm{G}(2 \mathrm{fd}, 2 \mathrm{p})$, cc-pVTZ and AUG-cc-pVTZ, where the three last are referred to as "B1", "B2" and "B2a", respectively. ${ }^{[14]}$ Conformational states were searched for by performing relaxed scans using the relatively inexpensive 6-31G(d) basis set, where the two dihedral angles $\Phi_{1}(\mathrm{C}=\mathrm{C}-\mathrm{C}-\mathrm{O})$ and $\Phi_{2}(\mathrm{C}-\mathrm{C}-\mathrm{O}-\mathrm{H})$, determining the $\mathrm{OH}$ group position, were varied. Structures relatively close to a local energy minimum were then subjected to full unconstrained geometry optimization.

The conformational states thus obtained were fully optimized using all other basis sets as well. The occupational probability $p_{i}$ of each conformer (i) is derived from the Gibbs distribution, i.e., $p_{i}=A$ $\exp \left(\mathrm{G}_{\mathrm{i}} / \mathrm{k}_{\mathrm{B}} \mathrm{T}\right)$, where $\mathrm{G}_{\mathrm{i}}=\mathrm{H}_{\mathrm{i}}-\mathrm{TS}_{\mathrm{i}}$ is the free energy of conformer (i), A follows from $\sum_{\mathrm{i}} \mathrm{pi}=1$, and $\mathrm{k}_{\mathrm{B}}$ is Boltzmanns constant. For each conformer and basis set a harmonic frequency calculation was performed at the optimized structure. An anharmonic frequency calculation was performed for the two lowest energy conformers as well using the 6-31G(d,p) basis set. Raman and IR intensities were calculated using the B1 basis set. All calculations were done using the very tight convergence criterion, ultrafine integration grid and fine for the SCF calculation.

\section{Results}

The band position difference derived from fitting the same band with Lorenzian or Gaussian functions was insignificant for those cases where the position could be determined reliably, and amounted for strong bands typically to $<0.02 \mathrm{~cm}^{-1}$. Thus the frequency error derived in most cases by large from the ASTM E 1840 standard combined with the instrumental repeatability error, which in total amounted to $\sim 1 \mathrm{~cm}^{-1}$ across the spectrum. The most intense solvent bands exclude a reliable detection of some FA bands. A typical example is depicted in fig. 2, where intense $\mathrm{C}(\mathrm{Cl})_{4}$ bands at 220, 315, 460, 760 and $790 \mathrm{~cm}^{-1}$ exclude detection of FA band (and give rise to very "noisy" intervals), whereas the weak and broad $1530 \mathrm{~cm}^{-1} \mathrm{C}(\mathrm{Cl})_{4}$ band poses no problems. A weak fluorescence background, increasing towards higher wavenumbers, is also noted.

\section{(Fig. 2)}

FA band positions differed little between the two solvents, and since most bands were detected using $\mathrm{C}(\mathrm{Cl})_{4}$ we record the positions obtained in this solvent except for a few cases, where these were reliably obtained only in toluene. For a few bands a concentration dependence of their position was recorded. This was then extrapolated to the infinite dilution limit (assuming the wavenumber shift to be linear in concentration). In table 2 we list the experimental fundamental frequencies together with the DFT results, which will be explained below.

In accordance with previous findings ${ }^{[9]}$ five conformational FA states were determined by the B3LYP/6-31G(d) search. The absence of imaginary frequencies for all conformers and basis sets confirmed these to represent true energy minima. Selected properties are listed in table 1 together with the occupational probability of each conformer. Thus in vacuum or in apolar weakly interacting solution the results all indicate a predominant occupation of the Skew 1 and Skew 3 conformers. For ease of comparison we adopt the Skew/Syn notation used previously. ${ }^{[9]}$ 
The absolute deviations averaged over all conformers of $\left(\Phi_{1}, \Phi_{2}\right)$ between the B3LYP/B2a and the previous MP2/6-31G $(\mathrm{d})$ results are $\left(\Delta \Phi_{1}, \Delta \Phi_{2}\right)_{\mathrm{AV}}=\left(3.7^{\circ}, 2.8^{\circ}\right)$, whereas those between B3LYP/B2a and B3LYP/B2 or B3LYP/B1 are $\left(0.9^{\circ}, 0.6^{\circ}\right)$ and $\left(0.1^{\circ}, 0.2^{\circ}\right)$, respectively. The largest discrepancy arises from the Syn $2\left(\Phi_{1}, \Phi_{2}\right)$ values, which equal $\left(10^{\circ}, 173^{\circ}\right)$ for the MP2/6$31 \mathrm{G}(\mathrm{d})$ calculations and $\left(0^{\circ}, 180^{\circ}\right)$ for the B3LYP calculations. The B3LYP results for Syn 2 were confirmed by starting full unconstrained geometry optimizations from geometries, which were partially optimized using the dihedral constraints $\left(\Phi_{1}, \Phi_{2}\right)=\left(10^{\circ}, 173^{\circ}\right)$ : This led to a monotonous energy decrease until the minimum at $\left(0^{\circ}, 180^{\circ}\right)$ was attained. In the following all reference to MP2 results refers to the same previous work ${ }^{[9]}$.

\section{(Table 1)}

The calculated vibrational properties of FA should be represented by a weighted superposition of those of the individual conformers. Since the Raman spectra do not convincingly exhibit resolved bands assignable to the two dominant conformers, the relevant calculated frequencies can for each normal mode be obtained either (1.) from the lowest energy Skew 3 conformer (neglecting all other conformers) or more appropriately (2.) from a frequency $\mathrm{k}_{\text {Calc }}$ obtained as a weighted average of the two (usually close lying) calculated frequencies $\left\{\mathrm{k}_{\text {Calc }}(1), \mathrm{k}_{\text {Calc }}(2)\right\}$ for each of the two lowest energy conformers Skew $1(\mathrm{i}=1)$ and Skew $3(\mathrm{i}=2)$, respectively. Each of the two weight factors is obtained as the B3LYP/B2a occupational probability $\mathrm{p}_{\mathrm{i}}$ multiplied by the calculated Raman intensity $\mathrm{R}(\mathrm{i})$. Thus the average frequency is $\mathrm{k}_{\text {Calc }}=\left(\mathrm{R}(1) \mathrm{p}_{1} \mathrm{k}_{\text {Calc }}(1)+\mathrm{R}(2) \mathrm{p}_{2} \mathrm{k}_{\text {Calc }}(2)\right) /\left(\mathrm{R}(1) \mathrm{p}_{1}+\right.$ $\left.\mathrm{R}(2) \mathrm{p}_{2}\right)$.

\section{(Table 2)}

The root-mean-square (RMS) error of $\mathrm{k}_{\text {Calc }}$ from experimental frequencies does not exhibit a significant dependency on the basis set used for the harmonic part. The largest absolute error is noted for the Me-CH stretching mode (\#28), which is underestimated by 6-31G(d,p): $74 \mathrm{~cm}^{-1}, \mathrm{~B} 1$ : $65 \mathrm{~cm}^{-1}, \mathrm{~B} 2: 75 \mathrm{~cm}^{-1}$, and B2a: $68 \mathrm{~cm}^{-1}$. From table 2 it is noted that large frequency errors appear to correlate with large frequency shifts of a normal mode between the different conformers. If normal mode \#28 is omitted the RMS error attains the values $6-31 \mathrm{G}(\mathrm{d}, \mathrm{p}): 10.0 \mathrm{~cm}^{-1}, \mathrm{~B} 1: 10.3 \mathrm{~cm}^{-1}$, B2: $8.4 \mathrm{~cm}^{-1}$, and B2a: $10.4 \mathrm{~cm}^{-1}$. If only the Skew 1 conformer is considered $\left(\mathrm{p}_{1}=1, \mathrm{p}_{2}=0, \# 28\right.$ omitted) the RMS error attains the values $6-31 \mathrm{G}(\mathrm{d}, \mathrm{p}): 12.4 \mathrm{~cm}^{-1}, \mathrm{~B} 1: 12.1 \mathrm{~cm}^{-1}, \mathrm{~B} 2: 9.8 \mathrm{~cm}^{-1}$, and B2a: $11.6 \mathrm{~cm}^{-1}$. In table 2 we list the optimal (B2: $8.4 \mathrm{~cm}^{-1}$ error) hybrid frequencies of $\mathrm{FA}$, for each of the two lowest energy conformers, together with the experimental frequencies.

\section{Discussion}

The present work qualitatively confirms the existence and $\left(\Phi_{1}, \Phi_{2}\right)$ values of five different FA conformers $^{[9]}$, two of which have markedly lower free energy than the remaining three. The structural discrepancies between B3LYP and MP2 conformations, noted especially for the Syn 2 $\left(\Phi_{1}, \Phi_{2}\right)$ values, may be due to the better MP2 level description of long range dispersion forces, but the relatively poor quality basis set used for the MP2 calculations makes comparisons difficult. The calculated B3LYP dipole moments show for all the large basis sets consistently the same ordering of magnitudes as the MP2/6-31G(d) results, where Skew 1 and Skew 3 have the largest values.

Both the previous MP2/6-31G(d) as well as the present B3LYP calculations identifies the Skew 3 $\left(\Phi_{1}=106^{\circ}, \Phi_{2}=60^{\circ}\right)$ as the lowest energy conformer. It should be noted that the present work 
reports free energies, whereas the previous MP2/6-31G(d) work reports only the SCF energies. As opposed to the previous calculations the B3LYP/B2a calculations do not identify the Syn 1 but the Skew $1\left(107^{\circ},-53^{\circ}\right)$ as the next lowest energy conformer $\Delta \mathrm{G}_{\mathrm{rel}}=43 \times 10^{-5}$ Hartree $(=1.1 \mathrm{~kJ} / \mathrm{mol})$ in much better accordance with experimental observations $\left(\Delta \mathrm{G}_{\mathrm{rel}}=1.5 \pm 0.4 \mathrm{~kJ} / \mathrm{mol}\right)^{[9]}$.

The third lowest energy conformer Syn $1\left(23^{\circ}, 58^{\circ}\right)$ has $\Delta \mathrm{G}_{\mathrm{rel}}=133 \times 10^{-5}$ Hartree $(=3.5 \mathrm{~kJ} / \mathrm{mol})$, and does thus, together with experimental observations ${ }^{[9]}$, indicate that the MP2/6-31G(d) result of $0.5 \mathrm{~kJ} / \mathrm{mol}$ was underestimated. This also holds for the more comparable SCF energies, where the $\mathrm{B} 3 \mathrm{LYP} / \mathrm{B} 2 \mathrm{a}$ calculation for Syn 1 yields $\mathrm{E}_{\mathrm{rel}}=150 \times 10^{-5}$ Hartree.

The B3LYP calculations indicate that all FA conformations are significantly populated $(>5 \%$ occupancy) at $\mathrm{T}=298 \mathrm{~K}$. Thus none of them can be neglected when it comes to reaction rate considerations. This is a consequence of the fact the $\Delta \mathrm{G}_{\text {rel }}$ values of all five conformers in vacuum are comparable to the value $\mathrm{k}_{\mathrm{B}} \mathrm{T}=94 \times 10^{-5}$ Hartree $=2.5 \mathrm{~kJ} / \mathrm{mol}(\mathrm{T}=298 \mathrm{~K})$. This is likely also the case in apolar solutions. The thermodynamic results combined with the dipole moment results suggest that the $\Delta \mathrm{G}_{\mathrm{rel}}$ ordering of the five conformational states may depend on the polarity of the environment. It is notable that the largest dipole moment Skew 1 conformer has a free energy very close to that of Skew 3, whereby the Skew 1 conformer in a polar environment could be more stable than Skew 3. The Skew 1 conformer may both be stabilized by specific hydrogen bonding to hydrogen bond acceptors (e.g., water molecules) and/or by the non-specific dipolar interaction with environment.

The inclusion of occupational probabilities leads to a small error improvement $\left(\sim 1-2 \mathrm{~cm}^{-1}\right)$ of the frequency calculations, which suggests that experimental bands may contain contributions from several conformers. Interestingly, a rather large RMS frequency error contribution arises from the Me-CH stretching mode (\#28). This error may be related to the limited size basis set used for the anharmonic correction, or to the B3LYP method itself, which may not model dispersion interactions sufficiently accurate. These interactions are likely to play a significant role for the energetics and electron density distribution attained for the FA conformers, where the Skew 1 and 3 conformers both may be stabilized by intramolecular $\mathrm{H}$ bonding between the $\mathrm{Me}-\mathrm{OH}$ and the $\pi$ electrons or the oxygen atom of the furan ring, respectively. We suggest that this anomalous large error, rather than pointing to basis set limitations, points to the limitations of the B3LYP functional in relation to intramolecular hydrogen bonded systems.

\section{Conclusion}

The B3LYP method has been used to describe the thermodynamics of FA conformers in vacuum or apolar solution. Irrespective of the basis set used all five FA conformers are populated at more than $5 \%$ probability level, and the lowest free energy Skew 3 (B2a: $46 \%$ ) and Skew 1 (B2a: $30 \%$ ) conformers are markedly more probable than the remaining three. Hence, in apolar environment FA reactions such as self-condensation (polymerization) occur initially from all five conformers appropriately weighted by their respective population levels. The MP2 method used previously for estimating the thermodynamics may have suffered from basis set limitations as a rather limited size basis set was used.

When a single normal mode is omitted the experimental and calculated B3LYP hybrid frequencies correspond well (with a RMS error of $8 \mathrm{~cm}^{-1}$ ) and allow for the qualitative assignment of most FA normal mode vibrations. The failure of the B3LYP frequency calculation to predict the Me-CH stretching mode frequencies may result from deficiencies of DFT to model long range dispersion interactions. This issue does, however, await future investigations. 


\section{Acknowledgements}

S. Barsberg thanks the ECOBINDERS project ("Furan and lignin based resins as eco-friendly and durable solutions for wood preservation, panel, board and design products", call FP6-2003-NMPSME-3) for financial support.

\section{Reference List}

[1] M. Choura, N. M. Belgacem, A. Gandini. Macromolecules 1996, 29(11), 3839-3850.

[2] M. Principe, P. Ortiz, R. Martinez. Polymer International 1999, 48(8), 637-641.

[3] I. S. Chuang, G. E. Maciel, G. E. Myers. Macromolecules 1984, 17(5), 1087-1090.

[4] R. Gonzalez, R. Martinez, P. Ortiz. Makromolekulare Chemie-Macromolecular Chemistry and Physics 1992, 193(1), 1-9.

[5] R. Gonzalez, J. M. Figueroa, H. Gonzalez. European Polymer Journal 2002, 38(2), 287297.

[6] S. Lande, M. Eikenes, M. Westin. Scandinavian Journal of Forest Research 2004, 19, 1421.

[7] S. Lande, M. Westin, M. Schneider. Scandinavian Journal of Forest Research 2004, 19, 22-30.

[8] A. Leonov, K. M. Marstokk, A. de Meijere, H. Mollendahl. Journal of Physical Chemistry A 2000, 104(19), 4421-4428.

[9] K. M. Marstokk, H. Mollendal. Acta Chemica Scandinavica 1994, 48(1), 25-31.

[10] V. Barone. Journal of Physical Chemistry A 2004, 108(18), 4146-4150.

[11] V. Barone, G. Festa, A. Grandi, N. Rega, N. Sanna. Chemical Physics Letters 2004, 388(46), 279-283.

[12] V. Barone. Chemical Physics Letters 2004, 383(5-6), 528-532. 
[13] V. Barone. Journal of Chemical Physics 2005, 122(1).

[14] M.J.Frisch, G.W.Trucks, H.B.Schlegel, G.E.Scuseria, M.A.Robb, J.R.Cheeseman, J.A.Montgomery, Jr., T. Vreven, K.N.Kudin, J.C.Burant, J.M.Millam, S.S.Iyengar, J.Tomasi, V.Barone, B.Mennucci, M.Cossi, G.Scalmani, N.Rega, G.A.Petersson, H.Nakatsuji, M.Hada, M.Ehara, K.Toyota, R.Fukuda, J.Hasegawa, M.Ishida, T.Nakajima, Y.Honda, O.Kitao, H.Nakai, M.Klene, X.Li, J.E.Knox, H.P.Hratchian, J.B.Cross, V.Bakken, C.Adamo, J.Jaramillo, R.Gomperts, R.E.Stratmann, O.Yazyev, A.J.Austin, R.Cammi, C.Pomelli, J.W.Ochterski, P.Y.Ayala, K.Morokuma, G.A.Voth, P.Salvador, J.J.Dannenberg, V.G.Zakrzewski, S.Dapprich, A.D.Daniels, M.C.Strain, O.Farkas, D.K.Malick, A.D.Rabuck, K.Raghavachari, J.B.Foresman, J.V.Ortiz, Q.Cui, A.G.Baboul, S.Clifford, J.Cioslowski, B.B.Stefanov, G.Liu, A.Liashenko, P.Piskorz, I.Komaromi, R.L.Martin, D.J.Fox, T.Keith, M.A.Al-Laham, C.Y.Peng, A.Nanayakkara, M.Challacombe, P.M.W.Gill, B.Johnson, W.Chen, M.W.Wong, C.Gonzalez, and J.A.Pople. Gaussian 03. 

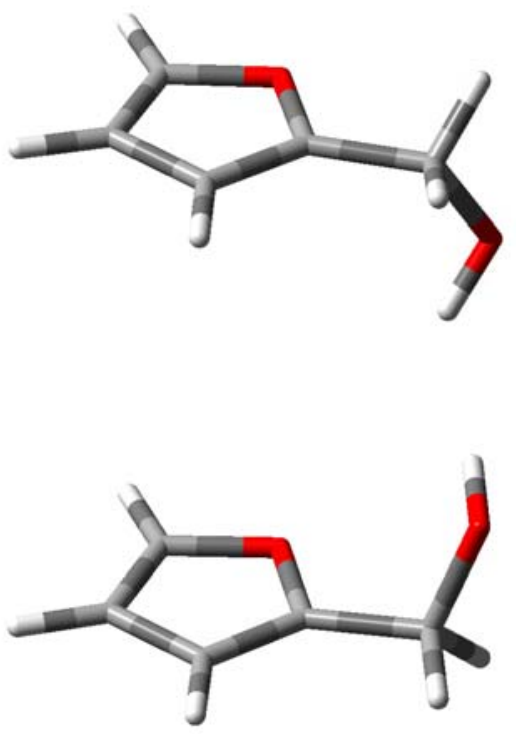

Figure 1: The experimentally determined lowest (bottom: Skew 3) and next lowest (top: Skew 1) energy FA conformers. 


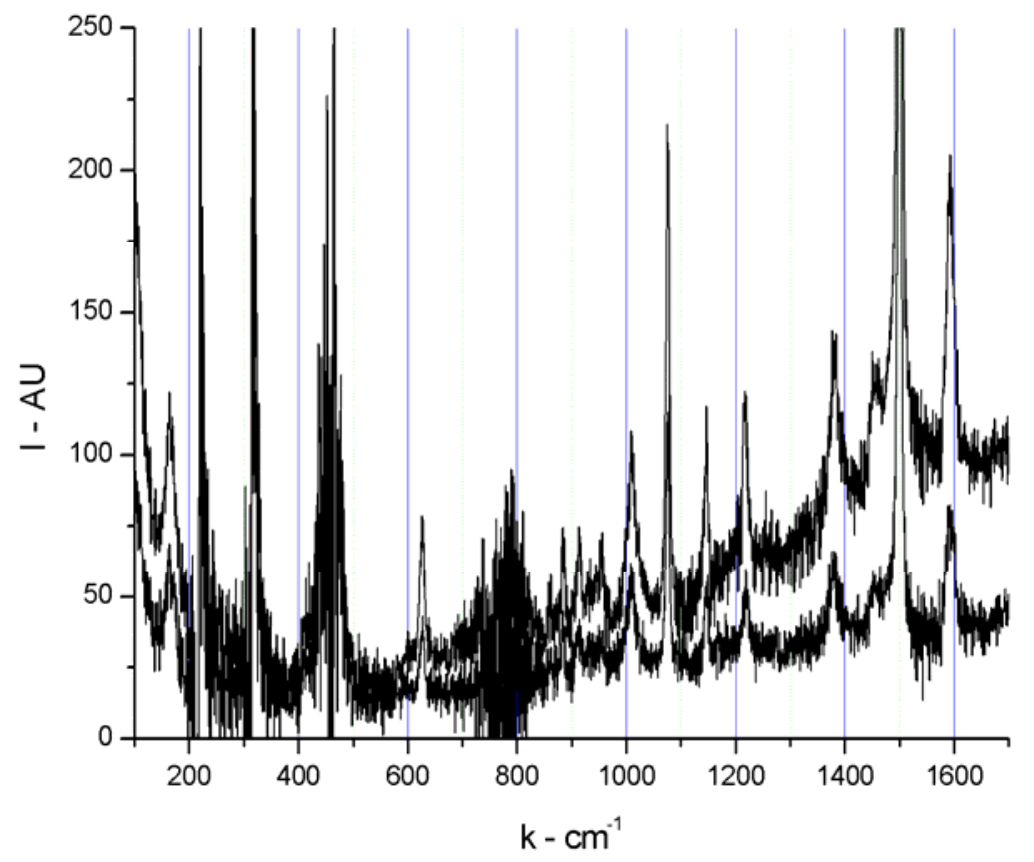

Figure 2: Raman spectra of the two lowest concentration samples of FA dissolved in $\mathrm{C}(\mathrm{Cl})_{4}$. The spectra are corrected only for the solvent background, i.e. $I=I(k)-f(k) I_{S}(k)$. The scattering intensity (I) is in arbitrary units (AU). 


\begin{tabular}{|c|c|c|c|c|c|c|}
\hline \multicolumn{2}{|c|}{ Conformer: } & \multirow{2}{*}{$\begin{array}{l}\text { Skew } 1 \\
107.4\end{array}$} & \multirow{2}{*}{$\begin{array}{l}\text { Skew } 2 \\
104.0\end{array}$} & \multirow{2}{*}{$\begin{array}{l}\text { Skew } 3 \\
105.9\end{array}$} & \multirow{2}{*}{$\begin{array}{l}\text { Syn } 1 \\
22.6\end{array}$} & \multirow{2}{*}{$\begin{array}{l}\text { Syn } 2 \\
0.0\end{array}$} \\
\hline$\Phi_{1}$ & $\mathrm{~B} 2 \mathrm{a}$ & & & & & \\
\hline & B2 & 108.2 & 105.1 & 106.5 & 20.7 & 0.0 \\
\hline & B1 & 107.5 & 104.0 & 106.2 & 22.5 & 0.0 \\
\hline \multirow[t]{3}{*}{$\Phi_{2}$} & $\mathrm{~B} 2 \mathrm{a}$ & -52.6 & 168.7 & 59.7 & 58.4 & 180.0 \\
\hline & B2 & -53.2 & 167.0 & 59.9 & 58.7 & 180.0 \\
\hline & $\mathrm{B} 1$ & -52.7 & 168.2 & 59.3 & 58.2 & 180.0 \\
\hline \multirow[t]{3}{*}{$\mathrm{d}\left(\mathrm{O}_{\mathrm{F}}-\mathrm{H}_{\mathrm{Me}}\right)$} & $\mathrm{B} 2 \mathrm{a}$ & 3.304 & 3.823 & 2.789 & 3.736 & 4.342 \\
\hline & B2 & 3.291 & 3.800 & 2.769 & 3.739 & 4.339 \\
\hline & B1 & 3.305 & 3.819 & 2.785 & 3.735 & 4.341 \\
\hline \multirow[t]{3}{*}{$\mu$} & $\mathrm{B} 2 \mathrm{a}$ & 2.247 & 1.566 & 1.613 & 1.346 & 1.210 \\
\hline & B2 & 2.118 & 1.492 & 1.523 & 1.318 & 1.262 \\
\hline & B1 & 2.296 & 1.599 & 1.655 & 1.384 & 1.242 \\
\hline \multirow[t]{3}{*}{$\Delta G$} & $\mathrm{~B} 2 \mathrm{a}$ & 42.7 & 175.7 & 0.0 & 133.4 & 197.1 \\
\hline & B2 & 37.9 & 200.5 & 0.0 & 91.2 & 147.3 \\
\hline & $\mathrm{B} 1$ & 45.0 & 184.6 & 0.0 & 133.6 & 152.8 \\
\hline \multirow[t]{3}{*}{$\mathrm{p}$} & B2a & 0.295 & 0.072 & 0.463 & 0.113 & 0.057 \\
\hline & B2 & 0.281 & 0.050 & 0.420 & 0.160 & 0.088 \\
\hline & B1 & 0.282 & 0.064 & 0.454 & 0.110 & 0.090 \\
\hline
\end{tabular}

Table 1: Selected structural parameters, dipole moments $(\mu)$, relative free energies $(\Delta G)$ and occupational probabilities ( $\mathrm{p}$ ) at $\mathrm{T}=298 \mathrm{~K}$ of the five FA conformers derived by $\mathrm{B} 3 \mathrm{LYP}$ calculations using the large basis sets $\mathrm{B} 1, \mathrm{~B} 2$ and $\mathrm{B} 2 \mathrm{a} . \Delta \mathrm{G}$ is relative to the free energy of the Skew 3 conformer. The units used are degrees $\left(\Phi_{1}, \Phi_{2}\right), \AA(\mathrm{d})$, Debye $(\mu)$ and $10^{-5}$ Hartree $(\Delta \mathrm{G})$. The largest basis set B2a results are emphasized in bold. 


\begin{tabular}{|c|c|c|c|c|c|c|c|c|}
\hline No & Exp & $\begin{array}{l}\text { Skew } 3 \\
\text { Calc. }\end{array}$ & $\mathbf{R}$ & IR & $\begin{array}{l}\text { Skew } 1 \\
\text { Calc. }\end{array}$ & $\mathbf{R}$ & IR & Assignment \\
\hline 33 & 3623 & 3630.8 & 0.511 & 0.311 & 3615.6 & 0.647 & 0.231 & $\mathrm{Me}-\mathrm{OH}$ str \\
\hline 32 & 3153 & 3141.7 & 1.208 & 0.001 & 3140.1 & 1.228 & 0.001 & $\mathrm{~F}-\mathrm{CH}$ str \\
\hline 31 & 3123 & 3116.8 & 0.639 & 0.002 & 3110.6 & 0.651 & 0.003 & $\mathrm{~F}-\mathrm{CH}$ str \\
\hline 30 & 3123 & 3114.1 & 0.746 & 0.025 & 3107.8 & 0.695 & 0.028 & $\mathrm{~F}-\mathrm{CH}$ str \\
\hline 29 & 2935 & 2964.1 & 0.636 & 0.108 & 2936.9 & 0.997 & 0.125 & $\mathrm{Me}-\mathrm{CH}$ str \\
\hline 28 & 2874 & 2770.5 & 1.432 & 0.389 & 2858.1 & 1.076 & 0.374 & $\mathrm{Me}-\mathrm{CH}$ str \\
\hline 27 & 1598 & 1596.9 & 0.204 & 0.007 & 1584.9 & 0.204 & 0.014 & F-CC str \\
\hline 26 & 1504 & 1496.5 & 1.000 & 0.106 & 1495.7 & 1.052 & 0.126 & F-CC str \\
\hline 25 & 1459 & 1455.4 & 0.073 & 0.024 & 1458.5 & 0.095 & 0.025 & $\mathrm{Me}-\mathrm{CH}$ bend \\
\hline 24 & 1385 & 1383.2 & 0.135 & 0.001 & 1387.9 & 0.163 & 0.165 & $\mathrm{~F}-\mathrm{CC} / \mathrm{CO}$ str \\
\hline 23 & NO & 1373.3 & 0.041 & 0.520 & 1376.6 & 0.065 & 0.421 & $\mathrm{Me}-\mathrm{CH} / \mathrm{OH}$ bend \\
\hline 22 & $\mathrm{NO}$ & 1327.7 & 0.082 & 0.032 & 1317.3 & 0.017 & 0.028 & $\mathrm{Me}-\mathrm{CH} / \mathrm{OH}$ bend \\
\hline 21 & $\mathrm{NO}$ & 1244.3 & 0.016 & 0.078 & 1238.4 & 0.012 & 0.076 & Collective \\
\hline 20 & 1221 & 1210.8 & 0.129 & 0.198 & 1215.2 & 0.137 & 0.075 & $\mathrm{~F}-\mathrm{CC} / \mathrm{CO}$ str Me-CC str \\
\hline 19 & NR & 1151.4 & 0.010 & 0.296 & 1159.0 & 0.056 & 0.152 & Collective \\
\hline 18 & 1150 & 1145.3 & 0.042 & 0.053 & 1150.7 & 0.057 & 0.266 & Collective \\
\hline 17 & 1079 & 1078.4 & 0.134 & 0.042 & 1083.2 & 0.117 & 0.047 & $\mathrm{~F}-\mathrm{CO}$ str $\mathrm{F}-\mathrm{CH}$ ip bend \\
\hline 16 & NR & 1009.5 & 0.028 & 0.213 & 1008.4 & 0.011 & 0.122 & $\mathrm{~F}-\mathrm{CH}$ ip bend \\
\hline 15 & 1012 & 1001.8 & 0.149 & 1.000 & 1008.0 & 0.135 & 0.960 & Me-CO str \\
\hline 14 & $951 \pm 2$ & 959.2 & 0.035 & 0.044 & 945.9 & 0.060 & 0.342 & Collective \\
\hline 13 & 915 & 904.5 & 0.027 & 0.393 & 913.1 & 0.024 & 0.167 & Collective \\
\hline 12 & 886 & 893.7 & 0.036 & 0.076 & 893.6 & 0.038 & 0.051 & F-CCC ip bend \\
\hline 11 & 863 & 873.9 & 0.010 & 0.003 & 872.3 & 0.008 & 0.011 & $\mathrm{~F}-\mathrm{CH}$ op bend \\
\hline 10 & $816^{*}$ & 817.9 & 0.010 & 0.119 & 818.4 & 0.011 & 0.126 & $\mathrm{~F}-\mathrm{CH}$ op bend \\
\hline 9 & $735^{*}$ & 745.7 & 0.004 & 0.555 & 745.3 & 0.005 & 0.605 & Collective $\mathrm{F}-\mathrm{CH}$ op bend \\
\hline 8 & $735^{\star}$ & 731.3 & 0.007 & 0.176 & 733.2 & 0.007 & 0.106 & Collective $\mathrm{F}-\mathrm{CH}$ op bend \\
\hline 7 & 628 & 632.5 & 0.037 & 0.049 & 631.6 & 0.036 & 0.055 & Collective \\
\hline 6 & 600 & 609.2 & 0.002 & 0.065 & 609.0 & 0.002 & 0.063 & F op bend \\
\hline 5 & $419^{*}$ & 408.3 & 0.026 & 0.103 & 399.5 & 0.026 & 0.168 & Collective \\
\hline 4 & $314 \pm 2 *$ & 311.0 & 0.011 & 0.461 & 295.3 & 0.007 & 0.399 & $\mathrm{Me}-\mathrm{OH}$ torsion \\
\hline 3 & NO & 251.7 & 0.008 & 0.747 & 242.4 & 0.005 & 0.738 & $\mathrm{Me}-\mathrm{OH}$ torsion \\
\hline 2 & $163 \pm 2$ & 148.9 & 0.027 & 0.006 & 148.0 & 0.031 & 0.004 & Me op bend \\
\hline 1 & $\mathrm{NO}$ & 63.9 & 0.011 & 0.025 & 63.0 & 0.014 & 0.011 & Me torsion \\
\hline
\end{tabular}

Table 2: Experimental and hybrid B2//6-31G(d,p) frequencies and vibrational assignments for the two lowest energy conformers. Raman (R) and IR intensities are in units of the Skew 3 mode \#26 Raman intensity (=109,0 A $4 / \mathrm{amu})$ and \#15 IR intensity (=110,9 KM/mole), respectively. Frequencies obtained in toluene are marked with "**". Fundamentals, which could not be observed are marked "NO" or, when not reliably resolved, with "NR". Frequency errors are $1 \mathrm{~cm}^{-1}$ unless otherwise stated. "F" and "Me" represent the furan ring and methanol parts of FA, respectively. In-plane and out-of-plane vibrations with respect to the furan ring are abbreviated "ip" and "op", respectively. 